\title{
PERSISTENT TRUNCUS ARTERIOSUS COMMUNIS WITH MICROPHTHALMOS, ORBITAL CYST AND POLYDACTYLY
}

BY

\author{
H. A. HARRIS, \\ Anatomy School, Cambridge, \\ AND \\ G. C. THOMSON, \\ University of the Witwatersrand, Johannesburg.
}

\section{Clinical record}

A white woman, aged seventeen, was admitted to hospital in labour. Since the onset of menstruation at fifteen years only six or seven periods had occurred, and the last period could not be accurately dated. The personal and family history was uneventful. A female child was delivered by forceps after a lengthy first stage and cried spontaneously; she was apparently well nourished, was $50 \mathrm{~cm}$. long and weighed $2,970 \mathrm{gm}$. (fig. 1). The lanugo was persistent and resembled that phase of distribution usually seen at the end of the eighth month. The orbits were sunken and the eyes were represented only by depressed slits $1 \mathrm{~cm}$. in length with an interorbital distance of $3 \mathrm{~cm}$. from one inner canthus to its fellow. Even with forcible retraction of the eyelids small eyeballs could barely be made out in the depths of the orbit. The ears were of the ' cauliflower' type and presented marked Darwinian tubercles. The neck and trunk showed no abnormality and the umbilical cord was normal. An accessory thumb was present on the right hand and the skiagram showed two phalanges therein, the web between the two thumbs being slightly distal to the level of the interphalangeal joints. The genitalia were normal and there was a well-marked sacral dimple.

The child nursed poorly and the weight loss over the first four days was normal. During this period spells of rapid breathing and slight cyanosis were observed. The heart was found to be enlarged to the left and there was a loud systolic murmur best heard over the apical and pulmonic areas. The child became more cyanotic, the temperature rose to $101^{\circ} \mathrm{F}$. and death occurred on the sixth day.

\section{Post-mortem findings}

The heart. The child was well nourished and there was marked livor mortis especially in the nails of the fingers and toes-a condition which is not infrequently associated with a congenital anomaly of the heart. The abdomen showed no abnormality except an incompletely descended caecum and appendix which were situated at the level of the right iliac crest. The lungs showed congestion and small areas of inflammation especially at the left base. The middle lobe of the right lung was not clearly demarcated from its neighbours and the interlobular fissures were shallow. The thymus was small and the pericardial sac globular in shape. The heart was enlarged especially on the right side and weighed $30 \mathrm{gm}$. It presented a single large artery at the base, a persistent truncus arteriosus, with no trace of the differentiation into pulmonary and aortic trunks. The truncus arteriosus 
arose from the upper margin of the right ventricle, and was continued as a normally situated aortic arch with the three main arteries to the head and neck in the normal order. The recurrent laryngeal nerves were normally situated. Right and left pulmonary arteries arose from the posterior aspect of the truncus communis arteriosus at a distance of $9 \mathrm{~mm}$. from its origin. The diameter of the right pulmonary artery was $4.5 \mathrm{~mm}$. and that of the left $4 \mathrm{~mm}$., the distance between the two at origin being about $2 \mathrm{~mm}$. The ductus arteriosus, $8 \mathrm{~mm}$. long and $1 \mathrm{~mm}$. in diameter, ran from the left pulmonary artery to the convexity of the arch of the aorta and was patent

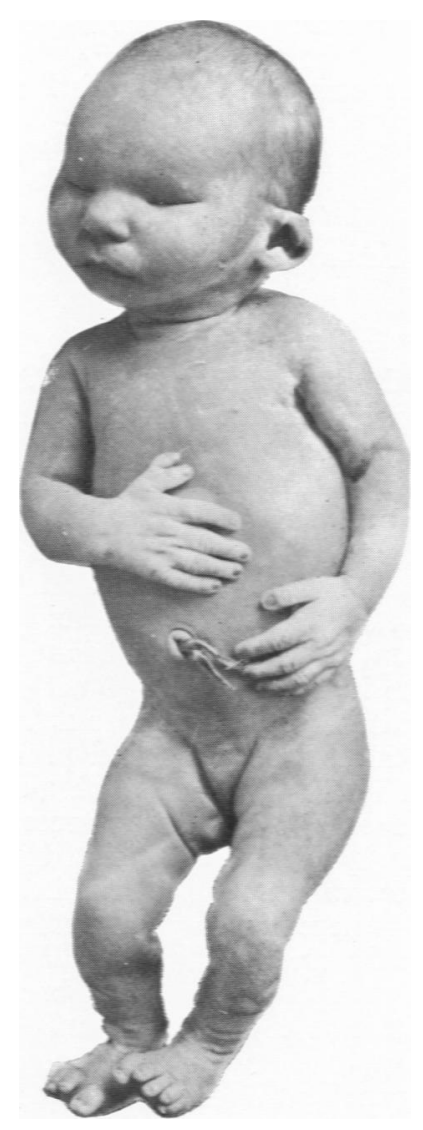

FIG. 1.-Post-mortem photograph of female babe, aged six days, with bilateral microphthalmos and polydactyly.

throughout. The pulmonary veins opened normally into the left auricle, the cavity of which was much smaller than normal and the auricular appendage was small and constricted at its union with the auricle. The superior and inferior venae cavae and the coronary sinus were normal, as were the Eustachian and Thebesian valves. The right atrium had a volume approximately five times that of the left atrium. The auricular septum was patent, and the foramen ovale measured $6 \mathrm{~mm}$. from the thick border of the septum secundum below to the thin margin of the septum primum 
above; antero-posteriorly on the sagittal plane the foramen measured $8 \mathrm{~mm}$. As a result of the marked dilatation of the right auricle and its auricular appendage, the opening of the superior vena cava into the atrium appeared to be guarded by two thickened valves - the septum secundum to the left and the fold between the vena cava and expanded auricular appendage to the right.

The right ventricle occupied four-fifths of the anterior aspect of the heart and one-half of the posterior aspect. The right ventricular cavity was dilated and the muscular wall was $4 \mathrm{~mm}$. thick, as compared with $5 \mathrm{~mm}$. in the left ventricle. The ventricular septum was deficient, and its free

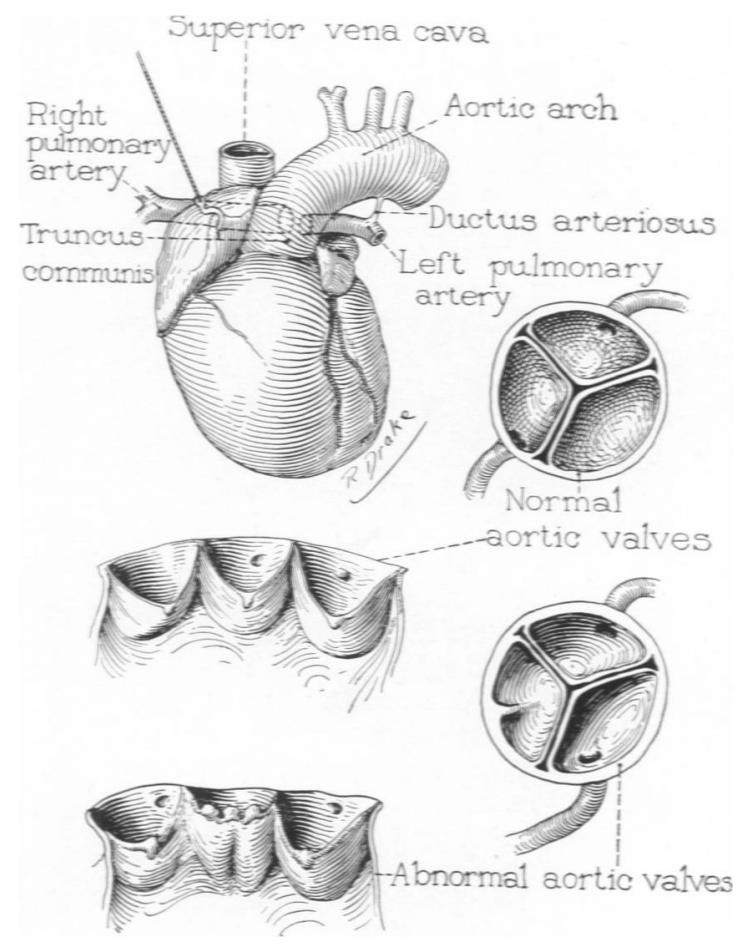

FIG. 2.-The heart of a female babe, aged 6 days, with truncus communis arteriosus from which the right and left pulmonary arteries arise. The abnormal aortic valves and coronary arteries are shown in comparison with the normal.

thickened margin directed backwards. On opening the truncus communis arteriosus by a continuation of the incision in the right rentricle, the free margin of the ventricular septum was concave and directed backwards and to the right so that the anterior proximal horn fused with the root of the truncus communis to the left anteriorly and the posterior distal horn fused with the truncus communis to the right posteriorly. The truncus communis was in more intimate relation to the dilated right ventricle than to the left, the free margin of the ventricular septum sitting so that the channel from the right ventricle to the truncus was about twice the area of that from the left. 
The orifice of the truncus communis arteriosus measured $2 \cdot 2 \mathrm{~cm}$. in perimeter and presented two large valves and two small valves, the two latter measuring in total length the same as either of the former. The two small valves were not entirely separated from one another as the line of attachment to the aortic wall which separated them failed to reach the free margin of the valves (fig. 2). Each of the small valves contained a thickened

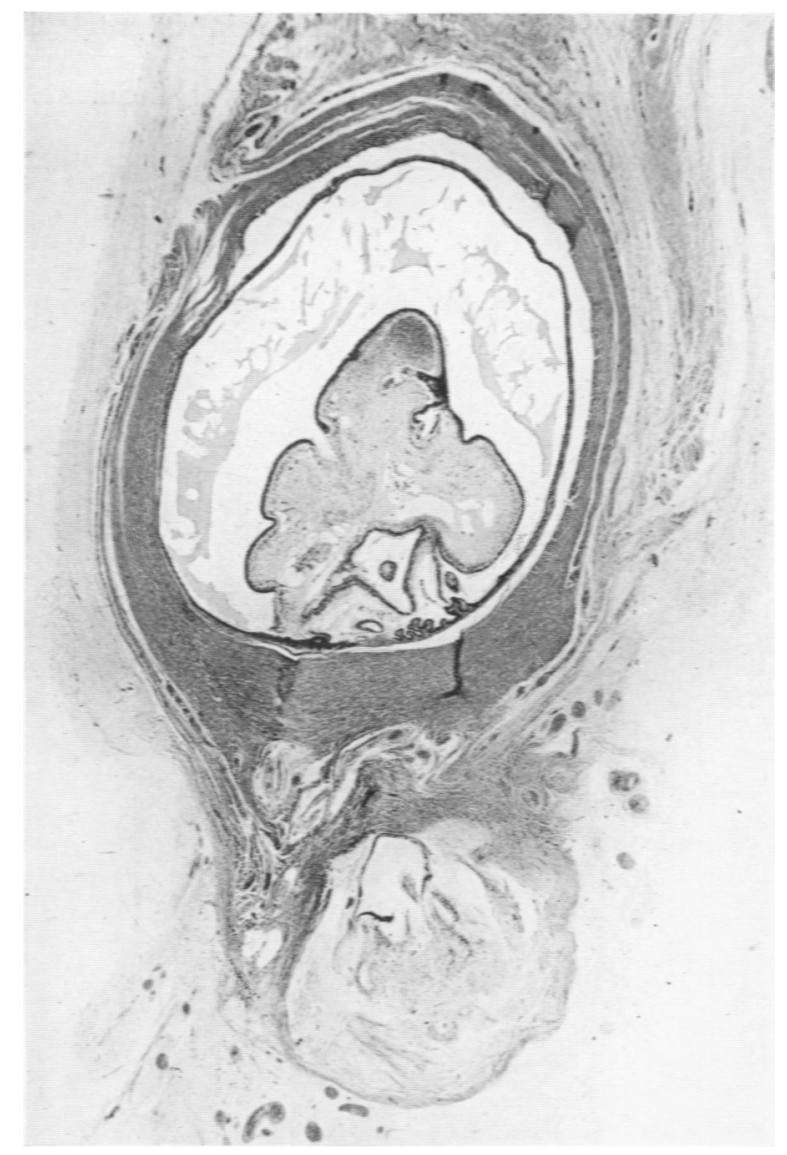

Fig. 3.-Section of the microphthalmic eyeball with cyst of the herniated retina. The pigmented layer of the retina lines the interior of the eyeball whereas the cellular layers of the retina are arranged around the vitreous and the hyaloid artery. Albuminous fluids occupies the intervening space.

nodule in the free margin thus suggesting that they should be regarded as separate entities, rather than as subdivisions of a single valve. All four valves were thickened and a considerable amount of fibrous tissue surrounded the corpus Arantii, so that the edges failed to meet closely. The right and left coronary arteries arose from the normal left anterior and the right posterior cusps; no accessory coronary arteries were found in relation to the two smaller cusps. 
The mitral and tricuspid valves were normal and at the line of attachment the former measured $3.2 \mathrm{~cm}$. and the latter $4.5 \mathrm{~cm}$. in circumference respectively. No abnormalities were noted in the papillary muscles and chordae tendinae. There was no naked-eye sign of endocarditis.

The eyes. On separating the small palpebral fissures both eyeballs were found to be small and sunken. The diameter of the eyeballs was about $6 \mathrm{~mm}$. The extrinsic muscles were all present, but small in size. The only abnormality was in the levator palpebrae superioris which was not as clearly separated from the superior rectus as usual. At the back of the eyeball was a small optic nerve of $0.5 \mathrm{~mm}$. diameter. A mass of tissue occupied the retrobulbar space and this was removed with the eyeball for microscopic examination. The sclera over the posterior part of the eyeball was dense and opaque, but more anteriorly a certain amount of pigment

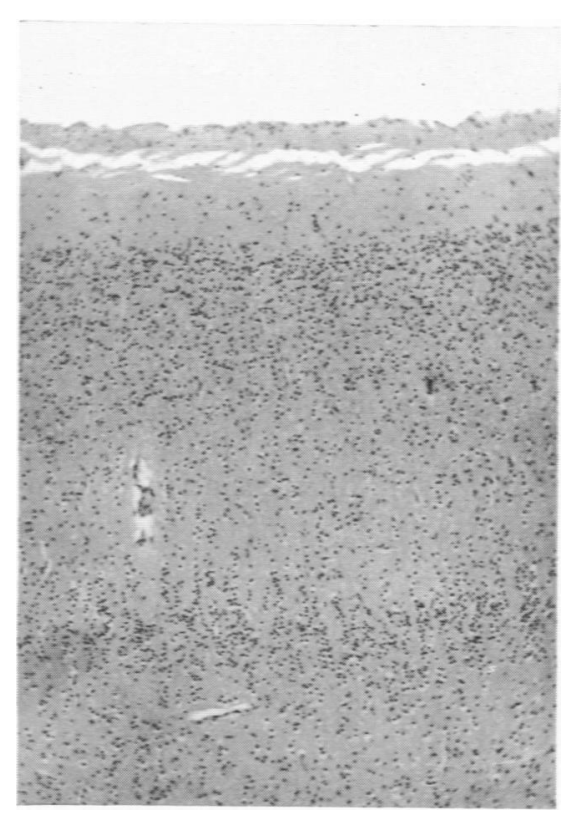

FIG. 4.-Microscopic section of the area striata of the visual cortex.

was visible through the thinner sclera. Details of the pupil and iris could not be made out as the anterior chamber of the eye was invaginated and the lens was dislocated downwards.

On histological section the eyeball showed extreme disorganisation. The retina was split between the basal pigment layer and the nerve cell layer proper so that the pigment layer lined the interior of the eyeball, and the cellular elements of the retina were thrown into folds surrounding a vitreous mass which contained a large hyaloid artery (fig. 3). An unorganized deposit of albuminous fluid lay between the retina and the pigment layer. Behind the eyeball was a cyst consisting of retinal elements surrcunded by a fairly well-defined connective tissue. According to the view of $\mathbf{W} \mathrm{blf}^{1}$ the cyst is formed as a result of the collection of aibuminous fluid between the retina and the pigment layer. This fluid 
causes the retina to be pushed out of the eyeball along the ocular fissure into the loose mesoderm. The evaginated portion of the retina forms a cyst which may grow to be larger than the eyeball itself. In this case the cellular elements of the retina in the cyst were not reversed, as is occasionally the case. It would appear that the retina was herniated at a time in embryonic life when the optic cup was incompletely invaginated and the chorioidal fissure was still incompletely closed at the pupillary margin. This stage of development, according to the views of Ida Mann², would be that of the fifth or sixth week of embryonic life.

The bony orbits were smaller than usual in their dimensions. On opening the skull the brain and cranial nerves appeared to be normal with the exception of the optic nerves and optic tracts. The optic nerves were only $0.5 \mathrm{~mm}$. in diameter and the optic tract $0.7 \mathrm{~mm}$. Scammon ${ }^{3}$ states that the average diameter of the optic nerve in the newborn is $2.7 \mathrm{~mm}$. On microscopic section both the optic nerve and optic tract displayed a considerable amount of aplasia, more marked in the former than the latter. The external geniculate body and the visual cortex, with a well developed stria of Gennari, were apparently normal (fig. 4).

The interest of these observations lies in the demonstration that a profound disorganization in one part of the visual mechanism, the eyeball and retina, involves to a decreasing degree the optic nerve and optic tract without causing any marked retrograde degeneration in the external geniculate body and the visual cortex. Had the babe lived for any considerable period of time, degeneration changes would probably have ensued in the visual cortex. Bolton ${ }^{4}$ examined the area striata in a case of complete congenital anophthalmus and maintained that both the extent of the visual cortex and the cytoarchitectonic differentiation of the layers in relation to the stria of Gennari was impaired, so that the area of the former was reduced by one half. In this case the lamination of the area striata corresponds closely to the normal.

\section{Embryological considerations}

Maude Abbott $^{5}$ has collected thirteen cases of persistent truncus arteriosus in a series of 651 cases of congenital cardiac anomalies. The duration of life varied from one hour to twelve years. Defect of the auricular septum characterized six of the cases, and defect of the ventricular septum characterized all thirteen, as the pars membranacea septi is developed from the pulmono-aortic septum. Eight of the cases presented a right-sided aortic arch; the right ventricle was hypertrophied in ten cases and the left ventricle in seven. Marked cyanosis was reported in three cases and a loud second 'pulmonic' sound in two. Six of the cases were complicated by defects in systems other than the vascular. Another case of persistent truncus arteriosus with defect of the auricular and rentricular septa was described by Harris ${ }^{6}$.

The present case shows a total defect of the pulmono-aortic septum including the pars membranacea septi. The deficiency in the auricular septum is not great. The pulmono-aortic septum proper begins to develop 
in the fifth week of embryonic life and the definite four-chambered heart is completely demarcated by the end of the seventh week. The interventricular septum commences to develop in the fourth week as a crescentic ridge on the inferior wall of the ventricle. The septum primum of the auricles begins to develop in the fifth week.

The associated anomalies in this case were bilateral microphthalmos, complete aplasia of the optic nerves and bilateral orbital cysts in direct communication with the interior of the eyeball. Is it possible to find a common time factor for the multiple anomalies? The condensation of the mesenchyme which is to form the dura mater sheath of the optic nerve is seen in a $10 \mathrm{~mm}$. embryo, but actual axis cylinders of the optic nerve are not normally seen until the $20 \mathrm{~mm}$. stage in the human. Again the anlage of the metacarpal of the thumb is clearly seen in the $16 \mathrm{~mm}$. stage, a time when the precartilaginous differentiaticn of the phalanges is rapidly taking place. This suggests that the disturbance of development in the eye and in the thumb occurred between the $10 \mathrm{~mm}$. and $16 \mathrm{~mm}$. stage, which is approximately the fifth week. At this time the eye already has a definite lens and abundant retinal pigment, but the optic stalk is still open and is about to undergo closure. The failure of the regular closure together with the appearance of the albuminous exudate in the retina at this time leads to the orbital cyst which contains imperfectly differentiated elements of the retina and pigmented layer. The sum total of the cardiac, optic and skeletal anomalies occurring in the fifth week are obriously not incompatible with the continuation of embryonic life and none of the special processes of grcwth and differentiaticn occurring after this period seem to have been interfered with except in so far as they were essentially consequent upon the main lesions. It is noteworthy that the peripheral parts of the vascular system, the urogenital systen and the lymphatic system display no anomalies as most of the critical processes therein antedate or postdate the aberrations associated with the fifth week of intra-uterine life.

\section{Summary}

1. A female infant of six days presents a truncus communis arteriosus, complete failure of the pulmono-aortic septum, deficient ventricular and auricular septa, microphthalmos, orbital cysts and polydactyly.

2. The site and nature of the anomalies pcint to an interference with normal growth during the fifth week of embryonic life, but the maternal history is negative. 
Thanks are due to Dr. Otto Schwartz and Dr. Paddock of the Department of Obstetrics at the Washington University Medical School, who afforded the opportunity for examining the case, and provided the clinical history and photograph.

\section{REFERENCES}

1. Wolff, E., The Pathology of the Eye, London, 1934, 175.

2. Mann, I., Brit. J. Ophthal., London, 1925, IX, 495.

3. Scammon, R. E., \& Armstrong, E. L., J. Comp. Neurol., Philadelphia, 1925, XXXVIII, 165.

4. Bolton, J. Shaw, Phil. Trans. Roy. Soc., Ser. B, London, 1900, CXCIII, 165.

5. Abbott, Maude E., Osler \& McCrae's System of Medicine, London, 1908, IV, 323.

6. Harris, H. A., Amer. J. Obst. \& Gynecol., St. Louis, 1926, XI, 767. 